\title{
Posttraumatic Bilateral Basal Ganglia Infarct in Pediatric Age-Clinical and Therapeutic Management: A Rare Case Report and Review of Literature
}

\author{
Tarun Varshney ${ }^{1}$ Vinod Sharma ${ }^{1} \quad$ Achal Sharma $^{1}$ \\ ${ }^{1}$ Department of Neurosurgery, SMS Medical College and Hospitals, \\ Jaipur, Rajasthan, India
}

Indian J Neurosurg 2019;8:61-63

\begin{abstract}
Address for correspondence Tarun Varshney, MCh (Neurosurgery), Department of Neurosurgery, SMS Medical College and Hospitals, Jaipur 302004, Rajasthan, India (e-mail: tarunvarshney1984@gmail.com).
\end{abstract}

\begin{abstract}
Ischemic stroke of basal ganglia after head trauma is rare in children younger than 18 months and accounts for less than $2 \%$ of all ischemic strokes in childhood. The clinical history of these lesions is particularly favorable because they are usually small and facial-brachial-crural hemiparesis is typical of this pathology that regresses over a period of time. The most effective therapeutic approach appears to be a conservative one, Keywords

- head trauma

- basal ganglia

- infarct although the best treatment regimen is still not well defined. It is necessary to exclude conditions such as heart disease, coagulopathies, and acute traumatic arterial dissections. The authors present a rare case of bilateral basal ganglia infarct in an 18-monthold child following head trauma managed conservatively with good recovery.
\end{abstract}

\section{Introduction}

Ischemia of the basal ganglia following head trauma in children younger than 18 months is rare and accounts for less than $2 \%$ of all ischemic strokes in childhood. ${ }^{1}$ It is caused by vasospasm of the lenticulostriate arteries. It manifests with nausea, vomiting, hemiparesis, and drowsiness, a clinical picture known as Juvenile Head Trauma Syndrome (JHTS). ${ }^{2}$ We present a rare case of bilateral basal ganglia infarct in an 18-month-old child following head trauma managed conservatively with good recovery.

\section{Case Report}

An 18-month-old boy presented to the emergency department following head injury. He fell from a height of approximately $50 \mathrm{~cm}$ onto a thinly carpeted floor. The child did not lose consciousness and had no history of seizure. He developed a right hemiparesis after 8 hours. Glasgow coma scale (GCS) score at the time of presentation was 14 , and the child was isochoric with isocyclic pupils, but there was a right brachiocrural hemiparesis with muscle strength of $2 / 5$. A computed tomographic (CT) scan of the head was done, which did not show any abnormalities. A hematologic workup was performed to exclude the possibility of

received

July 7, 2018

accepted after revision

July 9, 2018

published online

March 27, 2019 a genetic predisposition to thrombosis that includes coagulation time, bleeding time, prothrombin time, and D-dimer levels. These investigations were normal. Antinuclear antibody and anti-Ds DNA were negative. We also evaluated thyroid hormone assays that were normal. A magnetic resonance imaging (MRI) of the brain was performed, and it documented the presence of a ischemic lesion of bilateral caudate nucleus and on left involving internal capsule (-Fig. 1a-c). Magnetic resonance angiography (MRA) was normal. We could not carry out genetic testing due to financial restrictions with family. Acetyl salicylic acid was started at a dose of $50 \mathrm{mg} /$ day for a week. The child was discharged with improvement in motor power with strength of 3/5 in both the upper and the lower limbs, and is under regular
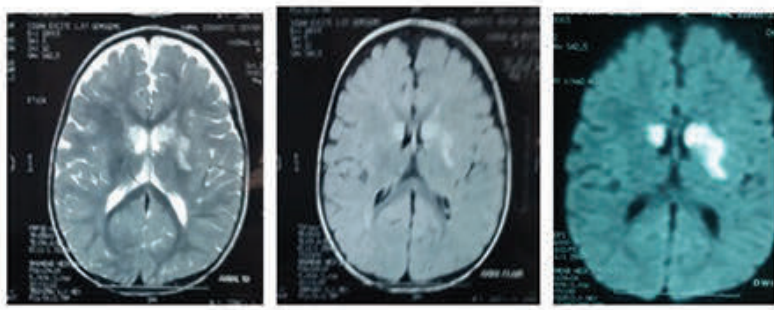

Fig. 1 MRI showing presence of a ischemic lesion of bilateral caudate nucleus and on left involving internal capsule.
DOI https://doi.org/

10.1055/s-0038-1668468.

ISSN 2277-954X.
License terms

(요 (1) $\Theta \circledast$ 
Table 1 Treatment, localization, and clinical outcomes in reported cases

\begin{tabular}{|l|l|l|l|l|l|}
\hline Patient & Age (mo)/sex & First symptom & $\begin{array}{l}\text { Lesion location (CT } \\
\text { scan, MRI, or both) }\end{array}$ & Treatment & $\begin{array}{l}\text { Clinical outcome (time } \\
\text { of follow-up in months) }\end{array}$ \\
\hline 1 & $17 /$ Male & Hemiparesis & Internal capsule & Conservative & Good/13 \\
\hline 2 & $17 /$ Male & Hemiparesis & Lentiform nucleus & Conservative & Good/13 \\
\hline 3 & $12 /$ Male & $\begin{array}{l}\text { Left-sided } \\
\text { hemiparesis }\end{array}$ & $\begin{array}{l}\text { Left internal capsule } \\
\text { and corona radiata }\end{array}$ & Conservative & Good/1 \\
\hline 4 & $12 /$ Female & $\begin{array}{l}\text { Left-sided } \\
\text { hemiparesis }\end{array}$ & $\begin{array}{l}\text { Right lentiform nucleus } \\
\text { and corona radiate }\end{array}$ & Conservative & Good/3 \\
\hline 5 & $\begin{array}{l}\text { Left-sided } \\
\text { hemiparesis }\end{array}$ & $\begin{array}{l}\text { Right lentiform nucleus } \\
\text { and corona radiate }\end{array}$ & Conservative & Good/3 \\
\hline 6 & $14 /$ Female & $\begin{array}{l}\text { Left-sided } \\
\text { hemiparesis }\end{array}$ & $\begin{array}{l}\text { Right basal ganglia and } \\
\text { corona radiata }\end{array}$ & Conservative & $\begin{array}{l}\text { Minimal pyramidal tract } \\
\text { signs in her left side/1 }\end{array}$ \\
\hline 7 & $\begin{array}{l}\text { Left upper motor } \\
\text { neuron 7th nerve } \\
\text { palsy and left } \\
\text { hemiparesis }\end{array}$ & $\begin{array}{l}\text { Bilateral basal ganglia, } \\
\text { internal capsule and } \\
\text { periventricular white } \\
\text { matter }\end{array}$ & Conservative & $\begin{array}{l}\text { Mild dysarthria and bilat- } \\
\text { eral extensor plantar/12 }\end{array}$ & \\
\hline 8 & $12 /$ Male & $\begin{array}{l}\text { Right hemiparesis } \\
\text { In left basal ganglia and } \\
\text { internal capsule }\end{array}$ & Conservative & Good/3 \\
\hline 9 & Right hemiparesis & $\begin{array}{l}\text { Bilateral caudate nucleus } \\
\text { and on left involving } \\
\text { internal capsule }\end{array}$ & Conservative & Good/5 \\
\hline
\end{tabular}

Abbreviations: $\mathrm{CT}$, computed tomography; MRI, magnetic resonance imaging.

follow-up. At the last follow-up 1 month prior to this manuscript being written, the motor power was the same, but the child was able to use the upper limb for holding and playing with toys and could walk with support with slight limping. A review of the literature was conducted using PubMed. We searched the terms "head trauma," "child," and "basal ganglia ischemia." We selected manuscripts reporting young patients aged 0 to 18 months presenting with lenticulocapsular ischemia due to head injury (-Table 1). Most of the cases have unilateral lesion, and only one case has bilateral lesion. This makes our case a rare entity as the lesions are mirror image infarct.

\section{Discussion}

Cerebral infarction after a head injury is an unusual mechanism of stroke in children. ${ }^{1}$ Secondary causes responsible for cerebral ischemic lesions in children younger than 18 months such as thrombophilia, arterial dissection, and embolic heart disease must be ruled out before labeling head injury as a cause of infarct. ${ }^{3,4}$ In cases similar to the one we describe here, it is necessary to exclude a possibility of surgical treatment of the lesions primarily responsible for symptoms such as bleeding, so the first investigation to be done is a CT scan. MRI of the brain with diffusion-weighted imaging is performed to look for infarct, and MRA is performed to look for anatomy of circle of Willis. The main etiology is due to the particular anatomical characteristics of the arteries and of the brain parenchyma at this age, especially the lenticulostriate arteries supplying the basal ganglia. These vessels create an acute angle with the middle cerebral artery, which is more acute in childhood than in the adulthood., Stretching and distorting the angle of perforating branches during trauma damage the vessel and cause a decrease in the blood flow. ${ }^{7}$ The sphenoid bone in children does not fully cover the temporal lobes and facilitate stretching of the lenticulostriate arteries by traumatic forces causing vasospasm and thrombosis. ${ }^{8}$ Another cause may be the friction generated between the lenticulostriate arteries and the brain parenchyma that occurs during the separation of the gray and white matter following a brain trauma in children causing vasospasm and thrombosis. This leads to shutdown of the lenticulostriate flow causing ischemia in the internal capsule with a subsequent facial-brachial-crural hemiparesis. ${ }^{5}$ Most children have been reported to recover completely following conservative therapy. ${ }^{7}$ A complete remission of facial-brachial-crural hemiparesis is typical of this pathology even with persistence of the ischemic area on MRI. The remission is due to the neuronal plasticity of the central nervous system. ${ }^{9}$

\section{Conclusion}

Posttraumatic bilateral basal ganglia infarct is a rare entity closely related to the anatomic peculiarities of the brain and skull base in childhood. Young patients should be closely monitored and managed conservatively. Secondary causes must be investigated and ruled out. The prognosis is good in these cases. 


\section{References}

1 Anderson V, Catroppa C, Morse S, Haritou F, Rosenfeld J. Functional plasticity or vulnerability after early brain injury? Pediatrics 2005;116(6):1374-1382

2 Dharker SR, Mittal RS, Bhargava N. Ischemic lesions in basal ganglia in children after minor head injury. Neurosurgery 1993;33(5):863-865

3 Fullerton HJ, Johnston SC, Smith WS. Arterial dissection and stroke in children. Neurology 2001;57(7):1155-1160

4 Haas DC, Pineda GS, Lourie H. Juvenile head trauma syndromes and their relationship to migraine. Arch Neurol 1975;32(11):727-730

5 Kieslich M, Fiedler A, Heller C, Kreuz W, Jacobi G. Minor head injury as cause and co-factor in the aetiology of stroke in childhood: a report of eight cases. J Neurol Neurosurg Psychiatry 2002;73(1):13-16

6 Maki Y, Akimoto H, Enomoto T. Injuries of basal ganglia following head trauma in children. Childs Brain 1980;7(3): 113-123

7 Shaffer L, Rich PM, Pohl KR, Ganesan V. Can mild head injury cause ischaemic stroke? Arch Dis Child 2003;88(3):267-269

8 Stein SC, Graham DI, Chen XH, Smith DH. Association between intravascular microthrombosis and cerebral ischemia in traumatic brain injury. Neurosurgery 2004;54(3):687-691, discussion 691

9 Umansky F, Gomes FB, Dujovny M, et al. The perforating branches of the middle cerebral artery. A microanatomical study. J Neurosurg 1985;62(2):261-268 